Ernil Hansen ${ }^{1}$

Thomas P. U. Wustrow ${ }^{2}$

Kurt Hannig ${ }^{3}$

${ }^{1}$ Department of Anesthesiology, University of Regensburg ${ }^{2}$ Department of

Othorhinolaryngology, Head and Neck Surgery, University of Munich

${ }^{3}$ Max-Planck-Institute of

Biochemistry, Martinsried

\section{Antigen-specific electrophoretic cell separation for immunological investigations}

Preincubation of human blood lymphocytes with cell surface antigen specific antibodies under non-capping conditions reduces the electrophoretic mobility of the corresponding lymphocyte subpopulation. Antigen-positive and antigen-negative cells can be separated by free flow electrophoresis with high yield, purity and viability. The use of fluorescence-labelled second antibodies augments the induced decrease in net surface charge density, and allows rapid detection of antigen-positive cells in the fractions of electrophoresis. Carrier-free cell electrophoresis of human peripheral blood lymphocytes after reaction with anti-IgM-antibody or the monoclonal antibodies OKT4 or OKT 8, and sandwich staining with tetrarhodamine isothiocyanatelabelled anti-IgG resulted in the large-scale separation of highly pure human B and T lymphocyte subpopulations. Their functional integrity was shown in assays of lymphocyte transformation and of antigen-specific induction and regulation of antibody synthesis in vitro. These separated lymphocyte subpopulations are useful tools for immunological investigations. While, for instance, the effects of drugs on human lymphocytes are obscured by coincident changes in cell composition of the peripheral blood tested that do not by themselves reflect whole body immunocompetence, the cell separation and in vitro assays at a defined cell number and cell composition allow the recording of quantitative changes in the function of different cell subpopulations. We studied the influence of the anesthetic thiopental on separated human lymphocyte subsets. In both polyclonal lectin stimulation and in vitro antibody production, thiopental exhibited a noncytotoxic suppression of lymphocyte functions. B-Cells, T-helper and T-suppressor cells were equally affected and showed the same dose response. The electrophoretic separation of cells after reaction with antibodies is applicable to a wide range of human lymphocyte subpopulations defined by specific antibodies. Their gentle isolation in large quantities is a powerful tool for investigations of the immune system.

\section{Introduction}

Investigations on the immune response and its regulation are hampered by the complexity of the immune system. As in other biochemical fields, a promising approach is to separate the individual constituents, to analyze them, and to study their function after reconstitution at defined conditions. Accordingly, cell separation techniques have greatly contributed to the increasing knowledge in immunology [1]. Since a number of lymphocyte functions are mediated through their cell surface, a separation based on differences in cell membrane properties, such as surface charge density, proved to be especially efficient. Preparative electrophoresis of cells became possible with the development of free flow electrophoresis [2]. Its application to lymphocytes led to the separation and characterization of a number of lymphocyte subpopulations with different functions and stages of differentiation ([3-9], for reviews see $[10,11])$. Especially the prominent difference in surface charge density between peripheral $T$ and $B$ lymphocytes in mice and rats was useful for large-scale isolation of these basic lymphocyte subsets.

Correspondence: Dr. med., Dr. rer. nat. Ernil Hansen, Bereich Anästhesie und Intensivmedizin der Universität Regensburg, Klinik und Poliklinik für Zahn-, Mund- und Kieferkrankheiten, Universitätsstr. 31, D-8400 Regensburg. Federal Republic of Germany

\footnotetext{
Abbreviations: ASECS, antigen-specific electrophoretic cell separation; ConA, concanavalin A; EM, electrophoretic mobility; FCS, fetal calf serum; FITC, fluorescein isothiocyanate; Ig, immunoglobulin; IL-1, interleukin 1; MNC, mononuclear cells; PHA, phytohemaglutinin; SRBC, sheep red blood cells; TRITC, tetrarhodamine isothiocyanate.
}

Free flow electrophoresis, however, failed to separate human $\mathrm{T}$ and $\mathrm{B}$ lymphocytes [12-17]. Besides, a much more detailed characterization of lymphocyte subsets has been achieved meanwhile using monoclonal antibodies [18]. This led us to the development of antigen-specific electrophoretic cell separation (ASECS), a method combining the high separation capacity of continuous free flow electrophoresis with the high specificity of antibody reactions [17]. This separation technique is based on the fact that immunoglobulins bear a much lower net negative charge than cell surfaces. Thus, the electrophoretic mobility (EM) of cell populations can be decreased by reaction with appropriate antibodies as has been shown in analytical studies (reviewed in [19]). In preparative separation sandwich techniques are applied for augmentation of the slowing effect, and a fluorescent antibody is used for convenient detection of the antigen-positive cells in the frac tions of electrophoresis. Optimal concentrations of the antibodies and noncapping conditions are essential for the induc tion of a marked decrease in EM of the cells.

While electrophoresis of unlabelled human peripheral blood lymphocytes resulted in a rather homogeneous distribution of the cells, in the electrophoresis of lymphocytes stained with anti-human IgM and fluorescein isothiocyanate (FITC)labelled anti-IgG antisera B cells appeared deflected to lower EM [17]. Flow cy tometric analy sis of the electrophoretic fractions showed that fluorescence intensity of the labelled cells increased with fraction number and lower EM. Thus, electrophoresis separated the antibody-labelled cells according to their surface antigen density. The mean EM of the B cells was reduced by about $20 \%$. When fractions were pooled in the region of low $\mathrm{EM}$ in order to include half of the antigen positive cells, purity of B cells was still $89 \%$. Cell viability ex 
ceeded $90 \%$ in all fractions. Cell loss during antibody treatment and cell electrophoresis was lower than $20 \%$. Similar results were obtained with the electrophoretic separation of a $\mathrm{T}$ cell subset after reaction with the monoclonal antibody T811 [17].

The method greatly expands the separation potential of free flow electrophoresis by changing it from a physical to an antibody-dependent, antigen-specific separation technique. Compared to other antibody-dependent cell separation methods, the main advantages of ASECS are that separation is carrier-free, and that separation capacity is high. In contrast to immunoabsorbent chromatography and rosetting techniques, antibody reaction and cell separation is without contact to solid surfaces or particles. In contrast to fluorescence-activated cell sorting, where maximal flow rate is 5000 cells per second [20], free flow electrophoresis allows separation of at least 100000 cells per second. The amount of separated cells is of critical importance for more detailed analysis of the immune system. Beside separation capacity, recovery, purity and viability, the functional integrity of the cells after separation determines the value of the method for immunological studies. We report on the application of human lymphocyte subpopulations separated by ASECS to assay the polyclonal lymphocyte stimulation by lectins, and an in vitro $\mathrm{B}$ cell immune response to sheep red blood cells (SRBC). The latter test system allowed the study of different lymphocyte functions, namely antigen recognition, antibody production by B cells, and its regulation by T cell subsets, in the same assay. The aim of the study was to investigate the effects of the anesthetic thiopental on human lymphocyte subpopulations.

\section{Materials and methods}

\subsection{Preparation of lymphocytes}

Two hundred $\mathrm{mL}$ of human peripheral blood were drawn from patients undergoing minor orthopedic surgery prior to induction of anesthesia, with their informed consent. The blood was defibrinated by gentle shaking in $50 \mathrm{~mL}$ plastic tubes containing 20 glass beads each. The clot was removed by filtration through layers of gauze, and platelets were discarded with the supernatant after centrifugation for $10 \mathrm{~min}$ at $200 \times g$ at room temperature. Mononuclear cells (MNC) were prepared by Ficoll-Hypaque density gradient centrifugation [21]. After resuspension of the cells in 3 volumes of Puck G (Difco, Detroit), and after layering of 2 volumes of cell suspension on top of 1 volume of MSL $^{\mathrm{R}}$ (Mediapharm, Aschaffenburg, d $1.077 \mathrm{~kg} / \mathrm{L}$ ), the centrifugation was performed for $30 \mathrm{~min}$ at $400 \times g$ at room temperature. The formed cell band was pipeted and the cells washed three times in cold Puck G medium by centrifugation for $10 \mathrm{~min}$ at $100 \times \mathrm{g}$. Their concentration was adjusted to $5 \times 10^{7}$ nucleated cells $/ \mathrm{mL}$. Cell viability, as tested by Trypan Blue exclusion, always exceeded $90 \%$. Contamination of these "lymphocyte preparations" by monocytes ranged from 5-12\%. Approximately $1 \times 10^{6}$ lymphocytes were recovered per $1 \mathrm{~mL}$ of blood.

\subsection{Antibody treatment}

Rabbit-anti-human-IgM antiserum (Behringwerke, Marburg) was used for labelling of B lymphocytes. Monoclonal antibody OKT8 (Ortho Pharmaceutical Corporation, New Jersey) was used to label CD $8^{+}$cells, i.e., T cells of the suppressor/cytotoxic subset. Monoclonal antibody OKT4 (Ortho) was used to label CD $4^{+}$cells, i.e., T cells of the helper/ inducer subset. Tetrarhodamine isothiocyanate (TRITC)conjugated goat-anti-rabbit-IgG immunoglobulin, and $\mathrm{rab}$ bit-anti-mouse-IgG immunoglobulin (Nordic Immunology, Tilburg), respectively, was applied as second antibody. TRITC-labelled goat-anti-rabbit-IgG immunoglobulin (Nordic) was used with the monoclonal antibodies for doublesandwich staining. TRITC-conjugates were chosen in preference to FITC-conjugates, because only the rhodamin label maintains the low isoelectric point of immunoglobulins, thus increasing the difference in charge density between the lymphocyte cell surface and bound immunoglobulins (Fig. 1). The second and third antibodies were absorbed with $1 / 10$ volume of human MNC isolated from buffy coat preparations by Ficoll-Hypaque density gradient centrifugation to reduce unspecific binding and cross reaction with human cell surface Ig [22].

All antisera were centrifuged before use at $15000 \times g$ for 30 min to remove protein aggregates. Antisera concentrations

electrophoretic migration path $(\mathrm{mm})$

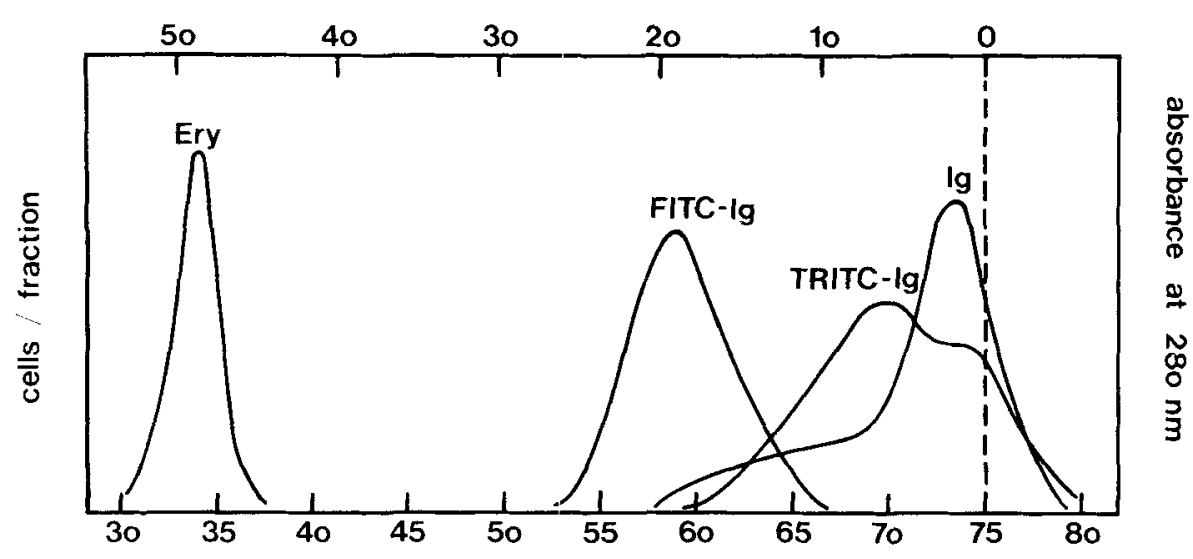

fraction number
Figure 1. EM of fluorescence-labelled im munoglobulins. EM of FITC-labelled, or TRITC-labelled goat-anti-rabbit Ig immunoglobulins was determined in free flow electrophoresis (effective field strength 74 $\mathrm{V} / \mathrm{cm}$ ), and was compared with human red blood cells as internal standard (anode) and with unlabelled goat Ig. The dashed line marks the position of sample application (isoelectric point). 
were adjusted to give an optimal uptake of antibodies by human lymphocytes, as deduced from titration experiments in immunotluorescence microscopy, to prevent nonspecific antibody binding and cell aggregation. Typical dilutions were $1: 4$ for the anti-human-IgM antiserum, 1:40 for the monoclonal antibodies, and 1:2 for the second and third antibodies, respectively. One $\mathrm{mL}$ of the proper antibody dilution was used for $5 \times 10^{7}$ nucleated cells. Noncapping conditions were provided by strictly working below $5^{\circ} \mathrm{C}$. Every antibody incubation was for $20 \mathrm{~min}$, followed by 2 washes in Puck G buffer by centrifugation at $100 \times g$ for $7 \mathrm{~min}$ to remove unbound immunoglobulins. With the last 2 washing steps the cells were transferred to the electrophoresis buffer of low ionic strength.

\subsection{Electrophoretic separation}

Free flow electrophoresis was performed as described previously [22]. The antibody-treated cells were adjusted to a concentration of $5 \times 10^{7} / \mathrm{mL}$ and subjected to electrophoresis at a flow rate of $6 \mathrm{~mL} / \mathrm{h}$. The effective field strength was $60-74 \mathrm{~V} / \mathrm{cm}$, the buffer flow rate was $500 \mathrm{~mL} / \mathrm{h}$. Fractions were collected in $10 \mathrm{~mL}$ tubes containing $1 \mathrm{~mL}$ of RPMI 1640 medium (Gibco-Europe, Karlsruhe) supplemented with $10 \%$ fetal calf serum (FCS) to minimize exposure of cells to low ionic strength and protein-free medium. Aliquots were analyzed for cell number and for percentage of fluorescencelabelled cells by fluorescence microscopy. Cell preparation and ASECS were performed under sterile conditions. Sterilization of the separation chamber and the electrode chambers was achieved by incubation with $3.5 \%$ formaldehyde for $4 \mathrm{~h}$ followed by a rinse with sterile, distilled water. Fractions containing more than $80 \%$ antigen-positive cells were pooled in the region of low EM. Fractions containing less than $5 \%$ antigen-positive cells were pooled in the region of high EM.

\subsection{Incubation with thiobarbiturate}

Pooled cells were resuspended in protein-substituted cell culture medium and adjusted to $10^{7}$ cells $/ \mathrm{mL}$. Thiopental (Trapanal $^{\mathrm{R}}$, Byk Gulden, Konstanz) was added in varying dilutions to give a final concentration from $0-250 \mu \mathrm{g} / \mathrm{mL}$. After incubation for $12 \mathrm{~h}$ at $4{ }^{\circ} \mathrm{C}$, thiopental was removed by centrifugation.

\subsection{Lectin stimulation}

After separation and exposure to thiopental, cells were cultured together with optimal doses of the lectin phytohemagglutinin (PHA) (Difco Lab., Detroit) or Concanavalin A (ConA, Serva, Heidelberg). Polyclonal mitogenic stimulation was assayed as $\left[{ }^{14} \mathrm{C}\right]$ thymidine incorporation [23]. Adherent cells were prepared by incubation of $\mathrm{MNC}$ in polystyrene Petri dishes and removal by EDTA incubation [24]. After irradiation with $40 \mathrm{~Gy}$ they were added to some of the cultures to supplement for monocytes depleted during cell separation. To remove cell-bound antibodies, capping was induced in samples of separated cells by preincubation for $30 \mathrm{~min}$ at $37^{\circ} \mathrm{C}$, and cells subsequently washed by centrifugation.

\subsection{SRBC-specific antibody production in vitro}

Antigen-specific induction and regulation of antibody syn thesis was studied in vitro $[25,26]$. MNC from human pe- ripheral blood were stimulated with $S R B C$ as foreign $T$ celldependent antigen. After 6 days the antigen-specific immune response was measured in the presence of complement by red blood cell lysis. For maximal antibody production in vitro, the human lymphocytes were activated in presence of interleukin 1 (IL-1), resulting in separation of functional suppressor cells after passage through Sephadex G-10 columns. In a ratio of $1: 10$ the isolated lymphocyte subclasses were added to this system after electrophoretic separation and thiopental treat ment to test for their regulatory or supplementary functions.

\section{Results}

\subsection{Separation of human lymphocyte subsets by ASECS}

Antibodies to IgM and a TRITC-labelled second antibody were used for ASECS of human B cells. A typical electrophoretic histogram of eight B cell separations is shown in Fig. 2A. Fluorescence-labelled, IgM-bearing cells were found and pooled in the region of low EM. While the proportion of $B$

\section{electrophoretic migration path $(\mathrm{mm})$}

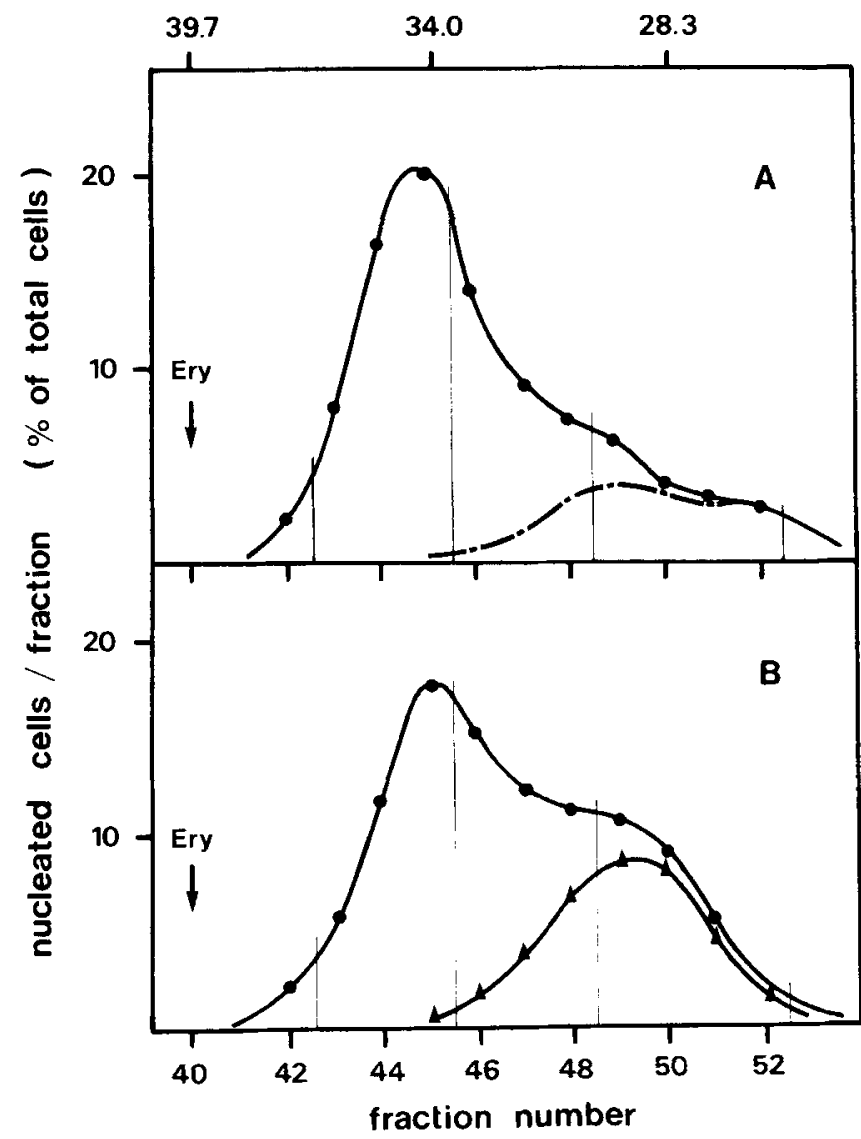

Figure 2. Antigen-specific electrophoretic cell separation of human B and T lymphocyte subpopulations. (A) Free flow electrophoresis of MNC after incubation with FITC-labelled rabbit-anti-human IgM antiserum. IgM+ cells (O) were pooled in the region of low EM (fractions 49-52), IgM- cells in the region of high EM (fractions 43-45). (B) Free flow electrophoresis of IgMcells after incubation with monoclonal antibody OKT8, rabbit-anti-mouse Ig immunoglobulin, and TRITC-labelled goat-anti-rabbit Ig immunoglobulin. Fractions were pooled as indicated to obtain $\mathrm{OKT} 8^{+}$cells $(\boldsymbol{\Delta})$ or OKT8- cells. The arrow marks the position of human red blood cells as internal standard (anode). 
cells in the patients varied from 14--21\%, their position relative to the main cell peak was constant. ASECS resulted in a B cell preparation of $9.2 \pm 1.1 \times 10^{6}$ cells per $100 \mathrm{~mL}$ of blood, with a purity of $92 \pm 2 \%$, and with a mean viability of $96 \pm 1 \%$. Nonlymphoid cells, mainly monocytes, constituted $7-10 \%$ of nucleated cells in the electrophoretic separation. They centered in the region of medium EM (fractions 46-49 in Fig. 2). Fractions pooled in the region of high EM contained less than $2 \% \mathrm{IgM}^{+}$cells. They represent $\mathrm{T}$ lymphocytes, as tested in immunofluorescence with the monoclonal antibody OKT 3 , at a rate of purity of more than $96 \%$. They were used in four experiments for further separation of T-lymphocyte subsets by ASECS (Fig. 2B). After incubation with the monoclonal antibody OK T8, a second antibody, and a fluorescence-labelled third antibody, cell electrophoresis separated $\mathrm{OKT} 8^{+}$cells in the region of low EPM from antigen-negative $\mathrm{T}$-lymphocytes in the region of high EM (Fig. 2B).

In twelve experiments MNC were used for ASECS of T lymphocyte subpopulations. The percentage of OK T8-binding $\mathrm{CD} 8^{+}$cells in the MNC preparations varied from

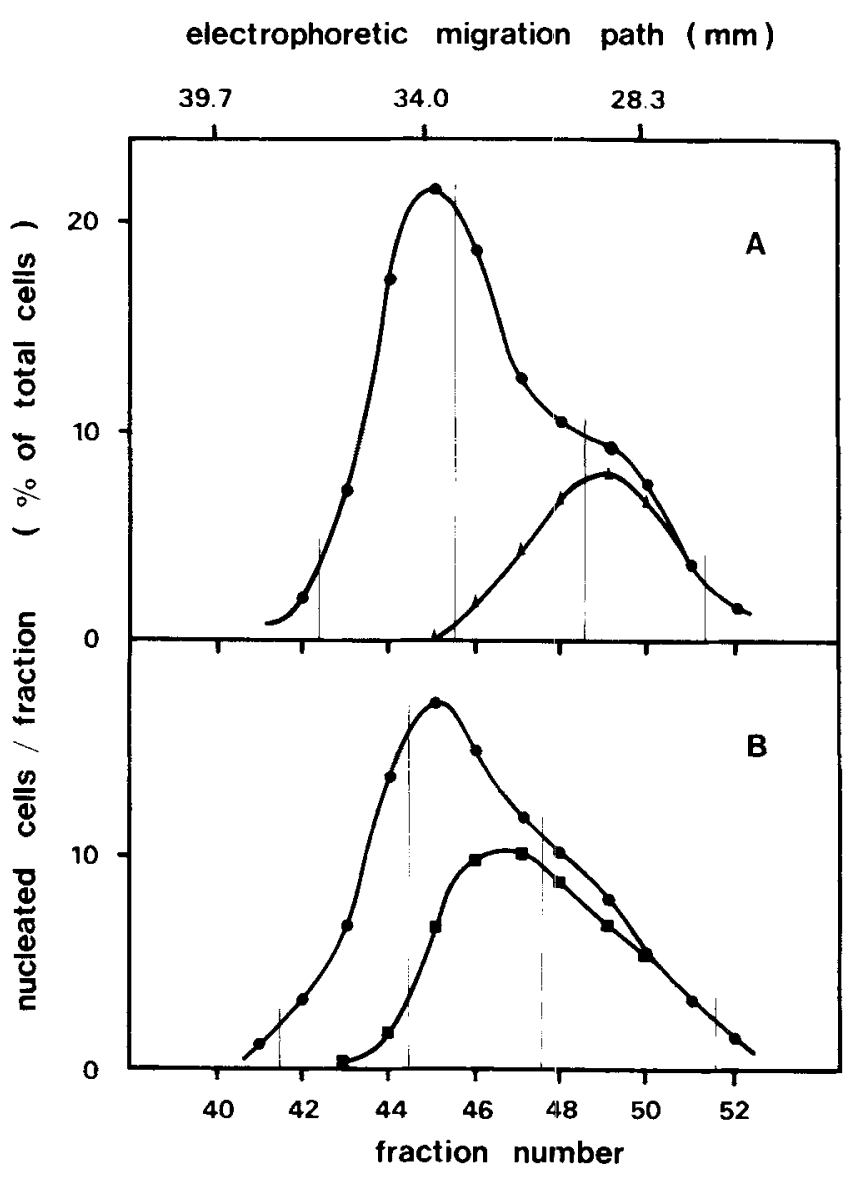

Figure 3. Antigen-specific electrophoretic cell separation of human $\mathrm{T}$ lymphocyte subpopulations. (A) Free flow electrophoresis of MNC after incubation with monoclonal antibody OKT8, rabbit-anti-mouse Ig immunoglobulin, and TRITC-labelled goat-anti-rabbit Ig immunoglobulin. OKT ${ }^{-}$cells $(\boldsymbol{\Delta})$ were pooled in the region of low EM (fractions 49-51), OKT8- cells in the region of high EM (fractions 42-44). (B) Free flow electrophoresis of MNC after incubation with monoclonal antibody OKT4, rabbit-anti-mouse Ig immunoglobulin, and TRITC-labelled goat-anti-rabbit Ig immunoglobulin. Fractions were pooled as indicated to obtain $\mathrm{OKT}^{+}(\boldsymbol{\square})$ and OKT4 cells. Human red blood cells as internal standard (anode) peaked in fraction 40. ( ) Nucleated cells.
22-28\%. After antibody treatment these lymphocytes appeared deflected to lower EM (Fig. 3A). Single fractions contained more than $95 \%$ antigen-positive cells. ASECS resulted in a CD $8^{+} \mathrm{T}$ cell preparation of $11.5 \pm 2.0 \times 10^{6}$ cells per 100 mL of blood, with a mean purity of $91 \pm 3 \%$ and with a mean viability of $96 \pm 2 \%$. In the region of high EM (fractions $43-45$ in Fig. $3 \mathrm{~A}$ ) cells mainly consisted of $\mathrm{CD} 4^{+}$cells, when tested in immunofluorescence using the monoclonal antibody OKT4. Less than $2 \%$ bore the T 8 marker. These OKT $8^{-}$cells were recovered in a quantity of $18.9 \pm 2.6 \times 10^{6}$ cells per $100 \mathrm{ml}$ of blood. The main cell peak in this separation of MNC was higher than in ASECS starting out from $\operatorname{IgM}^{-}$cells (Fig. 2B), where $B$ cells and monocytes were depleted by the prior separation.

In six experiments ASECS of B cells using anti-IgM antibodies and ASECS of T cell subpopulations using monoclonal antibody OK T8 were performed from blood aliquots of the same patient. In two patients the MNC preparation was used for both ASECS of OKT8 ${ }^{+} \mathrm{T}$ cells, and for ASECS of OKT4 ${ }^{+}$ cells (Fig. 3). After treatment with the monoclonal antibody OKT4 and a second antibody, and a fluorescence-labelled third antibody, the antigen-positive cells showed low EM in cell electrophoresis (Fig. 3B). Fractions pooled in the region of high EM mainly contained $\mathrm{OKT} 8^{+}$cells, as tested in immunofluorescence using the relevant antibody. Thus, ASECS allowed the separation of highly pure human lymphocyte subpopulations, namely $\mathrm{B}$ cells and $\mathrm{CD} 8^{+}$and CD $4^{+} \mathrm{T}$ cells. The latter $\mathrm{T}$ cell subsets were obtained both as antibody-reacted cells and as unreacted cells. The CD ${ }^{+}$cells of the suppressor/cytotoxic T cell subset, for instance, could be isolated as OKT8 ${ }^{+}$cells by ASECS using OKT8, or as OKT4 ${ }^{-}$cells by ASECS using OKT4 monoclonal antibody. This allowed the analysis of the influence of antibody treatment and electrophoretic separation on the immunological functions of the cells.

\subsection{Functional integrity of separated cells in lectin stimulation}

The T cell specific lectins PHA and ConA were used for polyclonal stimulation of lymphocytes. The mitogenic response was monitored as an increase in DNA metabolism. The mitogen responsiveness of lymphocytes varied from patient to patient, but the differences between isolated lymphocyte subpopulations were similar. The results of a representative experiment comparing the mitogenic response of different isolated $\mathrm{T}$ cell subsets are shown in Table $1 . \mathrm{OKT}^{+}$and OKT $8^{-}$cells were obtained from ASECS using monoclonal antibody OKT8, and $\mathrm{OKT}_{4}^{+}$and $\mathrm{OKT}^{-}$cells were prepared by ASECS using monoclonal antibody OKT4. Basal thymidine turnover was similar in all the electrophoretically separated cell preparations and in the MNC (Table 1). This further demonstrated the conservation of cell viability during ASECS. OKT $8^{+}$cells pooled in the region of low EM of the electrophoretic separation showed higher ConA responsiveness and lower PHA responsiveness than MNC, but similar magnitude. Thus, lymphocytes retained their ability to respond to lectin stimulation during antibody treatment and electrophoresis. Differences in the extent of stimulation by the lectins PHA and ConA were observed between $\mathrm{OKT} 8^{+}$and $\mathrm{OKT}_{4}{ }^{+}$cells. Again, a similar magnitude of response was seen, compared to $\mathrm{MNC}$. In contrast, $\mathrm{OKT}^{-}$and $\mathrm{OK} \mathrm{T4} 4^{-}$cells pooled in the region of high EM of the electrophoretic se- 
Table 1. Mitogenic response to lectin stimulation of human lymphocyte subpopulations separated by ASECS

\begin{tabular}{|c|c|c|c|}
\hline \multirow[b]{2}{*}{ Cells } & \multicolumn{3}{|c|}{ Mitogenic stimulation $\left(\mathrm{cpm} / 10^{5} \text { cells }\right)^{\mathrm{a})}$} \\
\hline & Control & $\mathrm{PHA}^{\mathrm{b})}$ & Con $A^{c)}$ \\
\hline MNC & $352 \pm 48$ & $3,035 \pm 452$ & $3,193 \pm 392$ \\
\hline OKT $8^{+}$ & $367 \pm 53$ & $2,378 \pm 348$ & $3,855 \pm 375$ \\
\hline OKT $8^{+}$stripped $\left.d\right)$ & $379 \pm 50$ & $2,509 \pm 407$ & $3,738 \pm 408$ \\
\hline $\mathrm{OKT}_{4}^{-}$ & $382 \pm 46$ & $782 \pm 167$ & $2,182 \pm 347$ \\
\hline $\mathrm{OKT}_{4}^{-}+$monocytese) & $376 \pm 55$ & $2,614 \pm 326$ & $3,624 \pm 331$ \\
\hline $\mathrm{OKT}^{-}$ & $384 \pm 43$ & $1,201 \pm 211$ & $1,610 \pm 368$ \\
\hline OKT $8^{-}+$monocytese) & $380 \pm 58$ & $4,115 \pm 478$ & $3,089 \pm 349$ \\
\hline $\mathrm{OKT} 4^{+}$ & $365 \pm 41$ & $3,970 \pm 509$ & $2,906 \pm 322$ \\
\hline
\end{tabular}

a) Each value was derived from 5 cell cultures

b) $2 \mu \mathrm{g} / \mathrm{mL}$

c) $4 \mu \mathrm{g} / \mathrm{mL}$

d) Cell bound antibodies removed by incubation at $37^{\circ} \mathrm{C}$ for $1 \mathrm{~h}$ and subsequent cell washes

e) Accessory cells prepared from peripheral blood MNC by adherence to plastic culture dishes, washes and removal by EDTA, and after mitotic inactivation by irradiation with $40 \mathrm{~Gy}$

parations showed a decreased responsiveness to mitogenic stimulation. Since this could reflect depletion of accessory cells during electrophoretic separation, irradiated adherent cells were added to some of the cultures. These cells, without contributing to the basal DNA metabolism, restored the mitogenic response to lectins in the cell populations of high EM. This supplementary effect of adherent cells was more pronounced in the response to PHA than in ConA stimulation.

OKT8 ${ }^{-}$and $\mathrm{OKT} 4^{+}$cells basically represent the same $\mathrm{T}$ cell population. Accordingly, the mitogenic responses of $\mathrm{OKT}^{+}$ and supplemented $\mathrm{OKT} 4^{-}$cells did not differ significantly, as $\mathrm{OKT} 4^{+}$and supplemented OK T8 cells did not differ. Thus, $\mathrm{T}$ lymphocyte subpopulations behaved the same with or without bound antibodies. To further test whether the antibodies used for separation interfered with the mitogenic response, or were mitogenic by itself, antibodies were stripped from $\mathrm{OKT} 8^{+}$cells in some samples prior to culture. After removal of bound antibodies the response to lectin stimulation was unchanged. No mitogenic effect was observed for the monoclonal antibodies OKT 8 and OKT4, in contrast to the monoclonal antibody OKT3 (data not shown). After electrophoretic separation $\mathrm{CD} 4^{+}$cells prepared as $\mathrm{OKT} 4^{+}$, or OKT $8^{-}$cells, and $\mathrm{CD} 8^{+}$cells prepared as $\mathrm{OKT} 8^{+}$or $\mathrm{OKT} 4$ cells revealed a characteristic difference in their responsiveness to the lectins PHA and ConA.

\subsection{Functional integrity of separated lymphocytes in the in vitro immune response to $\mathrm{SRBC}$}

B cells, macrophages, $\mathrm{T}$-helper and $\mathrm{T}$-suppressor cells cooperate in the immune response to SRBC. Sensitization of MNC with SRBC in vitro results in the generation of $B$ lymphocytes secreting antibodies that appear as plaque forming cells (Tables 2 and 4). The addition of cells modifies this response according to their function. The enriched lymphocyte subpopulations after ASECS were added to the system in only $1 / 10$ of the cell number. In the controls, ir radiated $\mathrm{MNC}$ were added to provide constant cell concentration. IL-1 substituted macrophages/monocytes that, therefore, were not limiting. While the response to SRBC differed from patient to patient, the effects of added cell populations were reproducible. $\mathrm{IgM}^{+}$cells enhanced the generation of
Table 2. Suppression of the mitogenic response to lectin stimulation of human lymphocyte subpopulations separated by ASECS after preincubation with thiopental

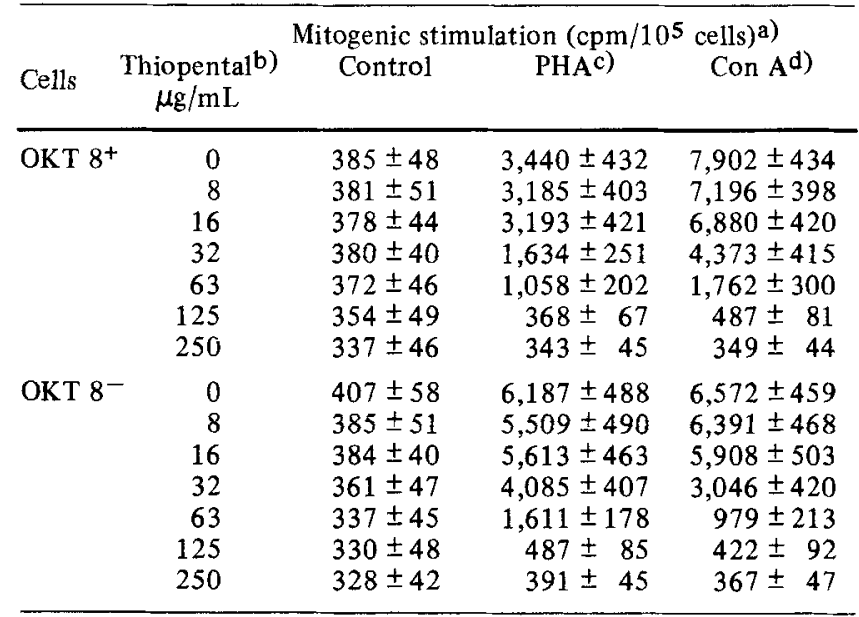

a) Each value was derived from 5 cell cultures

b) Preincubation with the barbiturate at $4^{\circ} \mathrm{C}$ for $12 \mathrm{~h}$

c) $2 \mu \mathrm{g} / \mathrm{mL}$

d) $4 \mu \mathrm{g} / \mathrm{mL}$

Table 3. In vitro immune response to SRBC of human MNC from peripheral blood after addition of lymphocy te subpopulations separated by ASECS

\begin{tabular}{|c|c|c|}
\hline \multirow{2}{*}{ Cells } & \multicolumn{2}{|c|}{ Plaque forming cells $/ 10^{5}$ cells ${ }^{a}$ ) } \\
\hline & Experiment 1 & Experiment 2 \\
\hline $\left.\mathrm{MNC}+\$ \mathrm{MNC}(1 / 10)^{\mathrm{b}}\right)$ & 65 & 30 \\
\hline $\mathrm{MNC}+\operatorname{IgM}^{+}(1 / 10)$ & n.d.c) & 112 \\
\hline $\mathrm{MNC}+\mathrm{OKT}^{+}(1 / 10)$ & 15 & 0 \\
\hline $\mathrm{MNC}+\mathrm{OKT}^{-}(1 / 10)$ & 172 & 62 \\
\hline $\mathrm{MNC}+\mathrm{OKT}^{+}(1 / 10)$ & 206 & n.d.c) \\
\hline
\end{tabular}

a) Plaque forming cells detected as red blood cell lysis after $6 \mathrm{~d}$ cell culture. Each value was determined from a pool of 8 cultures.

b) Addition of $1 / 10$ the cell number of mononuclear cells after irradiation with $40 \mathrm{~Gy}$

c) Not determined

Table 4. Suppression of lymphocyte functions in the in vitro immune response to SRBC after preincubation with thiopental

\begin{tabular}{|c|c|c|c|c|}
\hline \multirow[t]{2}{*}{ Cells } & \multicolumn{4}{|c|}{$\begin{array}{l}\left.\text { Plaque forming cells } / 10^{5} \text { cells } \mathrm{a}\right) \\
\left.\text { Thiopental reincubation }(\mu \mathrm{g} / \mathrm{mL})^{\mathrm{b}}\right)\end{array}$} \\
\hline & 0 & 25 & 63 & $155 \mu \mathrm{g} / \mathrm{mL}$ \\
\hline $\left.\mathrm{MNC}+\Sigma_{\mathrm{MNC}}(1 / 10)^{\mathrm{c}}\right)$ & 72 & n.d.d) & n.d. & n.d. \\
\hline $\mathrm{MNC}+\operatorname{IgM}^{+} \quad(1 / 10)$ & 130 & 75 & 46 & 24 \\
\hline $\mathrm{MNC}+\mathrm{OKT}^{+}(1 / 10)$ & 18 & 12 & 27 & 62 \\
\hline $\mathrm{MNC}^{+} \mathrm{OKT}^{-}(1 / 10)$ & 122 & 60 & 33 & 25 \\
\hline
\end{tabular}

a) Plaque forming cells detected as red cell lysis after 6 d cell culture Each value was determined from a pool of 8 cultures.

b) Preincubation of the lymphocyte subpopulations separated by ASECS with the barbiturate at $4^{\circ} \mathrm{C}$ for $12 \mathrm{~h}$

c) Addition of $1 / 10$ the cell number of mononuclear cells after irradiation with $40 \mathrm{~Gy}$

d) Not determined

plaque forming cells (Tables 2 and 4). One tenth of the cell number was found to add at least the same number of inducible antibody forming cells as in the original culture, reflecting the high enrichment during separation. Addition of OKT8 cells almost diminished the B cell response to SRBC, and thus identifies these lymphocytes as functional suppressor cells. In 
contrast, OKT8 ${ }^{-}$cells enhanced the development of antibody producing B cells. OKT $4^{+}$cells isolated by ASECS from the same patient produced an equivalent increase in plaque forming cells (Table 2). Thus, the bound antibodies were found not to interfere with the tested regulatory lymphocyte function. The experiments demonstrated the high preservation of functional integrity of the cells during ASECS.

\subsection{Effects of barbiturate on lymphocyte functions}

Thiopental, a barbiturate commonly used in anesthesia, was tested for its effects on in vitro lymphocyte functions. After incubation with the drug, the mitogenic response of the isolated lymphocyte subpopulations to the lectins ConA and PHA was suppressed in a concentration-dependent manner (Table 2). For both lectins and for both $T$ cell subsets blastogenesis was reduced by thiopental to about $50 \%$ at a concentration of $32 \mu \mathrm{g} / \mathrm{mL}$. The unstimulated DNA metabolism was decreased only slightly with the highest drug concentration. This showed that suppression of the mitogenic stimulation was not caused by a cytotoxic effect, but by interference with lymphocyte functions. In the assay of the in vitro immune response to $\mathrm{SRBC}$, thiopental suppressed the functions of the added lymphocyte subpopulations in a concentration-dependent manner (Table 4). Preincubation with the barbiturate prevented the increase in antibody-producing cells introduced by $\operatorname{IgM}^{+} \mathrm{B}$ cells. It reversed the suppression mediated by $\mathrm{OKT}^{+} \mathrm{T}$ cells. OKT 8 cells lost their ability to enhance the development of plaque forming cells. Actually, reversal of the effects of $\mathrm{IgM}^{+}$cells and $\mathrm{OKT} 8^{-}$cells on the generation of antigen-specific antibody-forming cells was already seen with 25 $\mu \mathrm{g}$ of thiopental per $\mathrm{mL}$, but with $155 \mu \mathrm{g}$ thiopental per $\mathrm{mL}$ the number of PFC decreased below control levels. This may be explained by a transfer of thiopental with the washed cells to the cell culture. Both B and T cells suppressed immune functions at the same thiopental concentration.

\section{Discussion}

\subsection{Immunosuppression and composition of peripheral blood}

After anesthesia and surgery, patients carry an increased risk of infections and tumor growth. Immunosuppression has been postulated and has been observed in vivo and in vitro(reviewed in [27-29]). The evaluation of the effects of anesthesia on the immune response is complicated by three problems, namely, (i) distinguishing the respective contributions of surgical stress and anesthesia to postoperative immunosuppression, (ii) distinguishing between changes in cell composition and cell functions, and (iii) distinguishing the interferences of anesthetics with different cellular components of the immune system. These difficulties are typical for immunological investigations and can be eliminated by cell separation techniques, and in vitro tests, as is demonstrated here.

The strongest immunosuppressive effects of all intravenous anesthetics have been reported for barbiturates, especially for thiopental [30]. It is not known if the various lymphocyte subpopulations are affected differently. Actually, it has been suggested that this suppression might be mediated by a stimulation of suppressor cell activity $[31,32]$. From postoperativeimmunoglobulin levels in peripheral blood it has been concluded that anesthesia does not interfere with B cell functions [33]. Besides the complexity of the immune network, the most severe problem in the investigation of the human immune system is whether the tested lymphoid organ is representative. The most readily available source of human lymphoid cells for immunological studies is peripheral blood. Accordingly, the vast majority of our knowledge about the human immune system has been gathered from studies on peripheral blood leukocytes. Most of the applied functional assays, however, are strongly dependent on the cell composition of the sample. Changes in the relative proportion of suppressor cells, for instance, will greatly influence the results. Such changes in cell composition of peripheral blood MNC have been observed for a number of conditions, including hyperglycemia, meditation, and also anesthesia [34-37]. These changes themselves are often misinterpreted as reflecting immunocompetence. Only $2 \%$ of the total lymphoid cell mass is contained in the blood. From the fact that states of severe immunodeficiencies, as in AIDS, or after chemotherapy, are also reflected in peripheral blood, it cannot be concluded that any change in cell composition in this compartment reflects whole body immunocompetence. Thus, a different cell composition observed in peripheral blood may be caused merely by a change in the homing pattern, but will strongly influence the results of in vitro tests. Therefore, a number of published results from immunological assays of peripheral blood lymphocytes have to be interpreted with care.

\subsection{Contribution of cell separation techniques}

Cell separation techniques can contribute to solving these problems. Applied to the evaluation of the effects of anesthesia on the immune response cell separation, in vitro incubation with the anesthetic, and in vitro assays of lymphocyte functions at defined cell number and cell composition allowed the recording of quantitative changes in the immune function of isolated lymphocyte subpopulations in response to thiopental, independent of factors such as surgical stress and induced changes in cell composition. Using this approach the following results were gained: (i) Thiopental exhibits a noncytotoxic suppression of lymphocyte functions. Cell viability was not reduced, nor was the number of cells decreased, but the reaction of the cells to stimuli was impaired. (ii) Thiopental suppresses in vitro the polyclonal response to mitogens and the $\mathrm{T}$ cell-dependent, antigen-specific response of $\mathrm{B}$ cells to SRBC. The lymphoid functions tested by these assays included antigen recognition, cell cooperation with nonlymphoid cells, cell activation and proliferation, helper function and suppression, mediator release and antibody synthesis, and covered $T$ and $B$ cell characteristics. (iii) B cells, $T$ helper and $T$ suppressor cells are equally affected. No stimulation of suppressor cells occurred that could account for the observed suppression.

Lymphocyte subsets from the same patient were tested and compared to exclude inter-individual variability in responsiveness. Inhibition of antibody synthesis and, specifically, impairment of B cell functions were observed, while such changes have not been indicated by the measurement of postoperative immunoglobulin levels in serum [33]. (iv) Suppression in vitro is concentration-dependent and is reached at the same concentration of thiopental for the different lymphocyte subpopulations. The thiopental concentrations that mediated strong suppression of lymphocyte functions are found well 
within the range observed after induction of anesthesia [38, 39] and during barbiturate therapy for brain protection in intensive care patients [30].

We conclude that the interference of barbiturates with immunocompetence is caused by an unspecific, suppressive effect on lymphocytes. While the inhibition of non-lymphoid cells observed in other studies $\{40,41]$ may contribute to the induced overall immunosuppression, a strong effect of the barbiturate on lymphocytes as mediators of the specific immune response was demonstrated here. The nonselective action of thiopental on lymphocytes of different origin and function, and in a similar dose dependency, is in accordance with the proposed nature of its anesthetic action, namely, a not receptor-mediated interference with cell membranes. These results on barbiturate-induced immunosuppression exemplarily demonstrate how detailed information can be gathered in immunological investigations by using cell separation techniques. For efficient application in immunological studies a method for cell separation must fulfill several requirements. It should preserve viability of the cells, and not interfere with their functions. High resolution is required to distinguish different cell populations. For comparison, separation should be not selective and no subfraction should be lost during the separation procedure. High recovery and high separation capacity is necessary to provide a sufficient number of cells for performance of complex immunological assays and for statistic validity, from a limited source of cells and within a reasonable amount of time. Finally, high specificity must allow separation of a spectrum of defined cell subpopulations to meet the requirements of immunology research today.

\subsection{Advantages of ASECS}

ASECS shows these characteristics. Carrier free electrophoresis avoids contact and interaction of cells with artificial surfaces. It provided lymphocytes unaltered in all parameters tested, and neither activation nor inactivation was observed during separation. Instead, the isolated lymphocyte subpopulations were comparable in their functional capability to unseparated cells, and activation or inactivation was inducible by mitogens, antigens or thiopental, respectively. ASECS is nonselective, as all the cells, antibody-reacted and-unreacted, are recovered. With the availability of appropriate corresponding antibodies and their proper combination it is possible to isolate a certain cell subset as antigen-positive cells, or as antigen-negative cells. In the described experiments OKT $8^{+}$ and $\mathrm{OKT}_{4}^{-}$cells, or $\mathrm{OKT}^{-}$and $\mathrm{OKT} 4^{+}$cells, showed equivalent functional capabilities. This possibility of positive and negative selection allowed comparison of $\mathrm{OKT}^{+}$with $\mathrm{OKT}_{4}^{+}$, and $\mathrm{OKT}^{-}$with $\mathrm{OKT}^{-}$cells, respectively, and greatly confirmed the observed differences between the $T$ cell subsets, since differences due to bound antibodies or to monocyte contamination were avoided. The purity of the isolated lymphocyte subpopulations led to the demonstration of marked differences in their functions. High cell recovery allowed the isolation and comparison of cell subsets from one patient, avoiding interindividual variability. Because of this variability, reflecting individual cell composition and state of activation etc., it is recommended not to pool cell electrophoretic data from different humans [42]. With the high number of cells obtained from ASECS, complex and multiple assays can be performed. Because of its specificity the method is applicable to the separation of a wide range of cell subpopulations for which specific antibodies are available.

Recently, electrophoretic separation of human T and B cells has been described using phosphate buffered saline for electrophoresis and accepting low separation capacity [43]. These results are in contrast to cell electrophoresis with low ionic strength buffers [12-17] and to analytical studies [44, 45]. If they are confirmed, they would still be restricted to the separation of B and T cells. ASECS expands the potentials of cell electrophoresis to the separation of various cell subpopulations using the relevant antibodies, thus meeting the requirements of modern immunologic investigations.

Following our description of ASECS, the method has been successfully adopted by other laboratories to the separation of mouse intestinal intraepithelial lymphocytes [46], and to human lymphocytes from patients with lymphoma [47]. With the growing spectrum of available lymphocyte differentiation markers, ASECS can provide a number of preparatively isolated lymphocyte subpopulations for detailed analysis of the immune system as demonstrated here.

The excellent technical assistance of Mrs. Carola Eckelt, Mrs. Rita Wiemeyer and Mrs. Sigrid Schöninger is gratefully appreciated.

Received March 15, 1989

\section{References}

11] Shortman, K., Contemp. Top. Mol. Immunol. 1974, 3, 161-173.

[2] Hannig, K., Methods Microbiol. 1971, 5, 513-548.

[3] Zeiller, K. and Hannig, K., Hoppe-Seyler's Z. Physiol. Chem. 1971, $352,1162-1167$.

[4] Andersson, L. C., Nordling, S. and Häyry, P., Cell. Immunol. 1972,8, 235-248.

[5] Zeiller, K., Pascher, G., Wagner, G., Liebich, H. G., Holzberg, E. and Hannig, K., Immunology 1974, 26, 995-1012.

[6] Zeiller, K., Pascher, G. and Hannig, K., Immunology 1976, 31, 863-880.

[7] Zeiller, K. and Hansen, E., J. Histochem. Cytochem. 1978, 26, 369-381.

18] Zeiller, K. and Hansen, E., Cell. Immunol. 1979, 44, 381-394.

[9] Hansen, E., Blut 1982, 44, 141-150.

[10] Hannig, K., Electrophoresis 1982, 3, 235-243.

[11] Hansen, E, in: Schütt, W. and Klinkman, H. (Eds.), Cell Electrophoresis, Walter de Gruyter, Berlin 1985, pp. 287-304

[12] Stein, G., Flad, H. D., Pabst, R. and Trepel, F., Biomedicine 1973, 19 , 388-395.

[13] Ault, K. A., Griffith, A. L., Platsoucas, C. D. and Catsimpoolas, N., J. Immunol. 1976. 117. 1406-1414.

[14] Levy, E. M., Silverman, S., Schmid, K. and Cooperband, S. R., Cell Immunol. 1978, 40, 222-229.

[15] Chollet, P. H., Herve, P., Chassagne, J., Masse, M., Plague, R. and Peters, A., Biomedicine 1978, 28, 119-124.

[16] Born, B., Nebe, C. T., in: Schütt, W. and Klinkmann, H. (Eds.), Cell Electrophoresis, Walter de Gruyter, Berlin 1985, pp. 305-311.

[17] Hansen, E. and Hannig, K., J.Immunol. Methods 1982,51,197-208.

[18] Reinherz, E. L., Moretta, L., Roper, M., Breard, J. M., Mingari, M. C., Cooper, M. D. and Schlossman, S. F., J. Exp. Med. 1980, 151, 969-978.

119] Sherbet, G. V., The Biophysical Characterization of the Cell Surface, Academic Press, New York 1978, pp. 36-145.

[20] Parks, D. R, and Herzenberg, L. A., Methods Enzymol. 1984, 108, $197-241$. 
121) Böyum, A., Scand.J. Clin. Lab. Invest 1968, 21, 31-39.

122] Hansen, E. and Hannig, K., Methods Enzymol. 1984, 108, 180-197.

[23] Bauer, J. and Hannig, K., Electrophoresis 1985, 6, 301-306.

[24] Karen, H. S., Anderson, S. J., Fisher, D. G., Copeland, S. C. and Jensen, P. J., J. Immunol. 1981, 127, 2007-2013.

$125\}$ Hoffmann, M. K.. Proc. Natl, Acad. Sci. USA 1980,77,1139-1143.

[26] Wustrow, T. P. U., Laryngo-Rhino. Otol. 1989, 68, in press.

[27] Moudgil, G. C. and Wade, A. G., Br. J. Anaesth. 1976, 48, 31-39.

|28| Walton, B., Anaesthesia 1978, 33,322-348.

129] Watkins, J., Clinics Anaesthesiol. 1984, 2, 463-483.

1301 Neuwelt, E. A., Kichuchi, K., Hill, S. A., Lipsky, P. and Frenkel, E. $J$. Neurosurg. 1982, 54, 254-259.

(31) Schmucker, P., Hammer, C. and Peter, K., Anaesthesist 1983, 32, 276-277.

132] Lovett, E. J., Varani, J. and Lundy, J., J. Surg. Oncol. 1983, 22, 26-32.

[33] Fuller, J. M. and Keyser, J. W., Clin. Chem. 1975, 21, 667-675.

[34] Cullen, B. F. and van Belle, G., Anaesthesiology 1975,43, 563-569.

[35] Hansbrough, J. F., Bender, E. M., Zapata-Sirvent, R. and Anderson, J., Am. J. Surg. 1984, I84, 303-307.

[36] Hole, A. and Bakke, O., Acta Anaesthesiol. Scand. 1984, 28, $296-300$
[37] Kaebisch, S., Zitnik, B., Krumholz, W., Lohmeyer, J., Pralle, H., Biscoping, J. and Hempelmann, G., Anästh. Intensivther. Notfallmed. 1986, 21, 327-332.

[38\} Brodie, B. B., Mark, L. C., Papper, E. M., Lief, P. A.. Bernstein, E. and Rovenstine, E. A., J. Pharmacol. Exp. Therapy 1950, 98, 85-92.

[39] Price, H. L., Anesthesiology 1960, 21, 40-45.

[40] Bardosi, L. and Tekeres, M., Br. J. Anaesth. 1985, 57, 520-523.

[41] Knudsen, F., Klausen, N. O., Ferguson, A. H. and Pedersen, J. O., Acta A naesthesiol. Scand. 1987, 31,93-95.

[42] Vassar, P.S., Levy, E. M. and Brooks, D.E.,Cell.Immunol. 1976,21, 257-271.

[43] Baier, T. G., Weber, G., Hartmann, K., Heinrich, U. and Schoenberg, D., Anal. Biochem. 1988, 171,91-95.

[44] Pretlow, T.G. and Pretlow, T. P., Int. Rev. Cytol. 1979,61,85-128.

145] Merishi, J. N., Wioland, M. and Gomariz-Zilber, E., in: Schüt, W. and Klinkman, H. (Eds.), Cell Electrophoresis, Walter de Gruyter, Berlin 1985, pp. 411-420.

[46] Cohly, van Oss, C., Weiser, M. and Abini, B., in: Schütt, W. and Klinkman, H. (Eds.), Cell Electrophoresis, Walter de Gruyter, Berlin 1985, pp. 603-609.

[47] Bohn, B. and Nebe, C. T., in:Schütt, W. and Klinkman, H. (Eds.), Cel Electrophoresis, Walter de Gruyter, Berlin 1985, pp. 305-311.

\section{Shoji Harada \\ Institute of Community Medicine, University of Tsukuba}

\section{Polymorphism of aldehyde dehydrogenase and its application to alcoholism}

\begin{abstract}
Aldehyde dehydrogenase (ALDH) consists of four different isozymes (I, II, III, IV). Among these, ALDH I shows genetic polymorphism (normal and deficient) in a population of Mongoloid origin. The significantly lower frequency of ALDH I deficiency was found in alcoholic patients compared with healthy controls. ALDH I deficiency is one of the important genetic factors in regulating alcohol consumption and plays a protective role against alcoholism. Population genetic studies on ALDH I deficiency in different ethnic groups indicate that ALDH deficiency was found only in Mongoloid population groups.
\end{abstract}

\section{Introduction}

NAD-Dependent aldehyde dehydrogenase (ALDH, EC 1.2.1.3.) is the main enzyme involved in the oxidation of acetaldehyde, which is the primary product of alcohol metabolism in humans. Human ALDH isozymes consist of four different components (ALDH I, II, III and IV) as revealed by using separation techniques such as electrophoresis and isoelectric focusing [1-3]. Among these isozymes, ALDH I and II mainly contribute to the oxidation of acetaldehyde. The faster migrating component, $\operatorname{ALDH~I~}\left(\mathrm{E}_{2}\right)$, is found predominantly in mitochondria and has a low $K_{\mathrm{M}}$ for acetyldenyde. On the other hand, the cytosolic enzyme, $\operatorname{ALDHII}\left(\mathrm{E}_{1}\right)$, is less anodal in electrophoretic migration and possesses a higher $K_{\mathrm{M}}$ value for acetaldehyde. Our previous studies [4-6] confirmed that Japanese and other Mongoloid subjects are deficient in ALDH I isozyme, while Caucasian populations possess both enzymes. Also, we reported that the deficiency of ALDH isozyme is responsible for higher acetaldehyde levels and the

Correspondence: Dr. Soji Harada, Institute of Community Medicine, University of Tsukuba, 1-1-1 Tennodai, Tsukuba, Ibanagi-Ken 305, Japan

Abbreviation: ALDH, aldehyde dehydrogenase flushing symptom, including other vasomoter symptoms, after alcohol intake $[7,8]$. Subsequent studies indicated that the frequency of the deficiency in ALDH I was significantly lower in alcoholics than in healthy controls $[9,10]$. These data suggest that individuals deficient in ALDH I isozyme may refrain from excessive drinking of alcohol due to averse reactions caused by raised blood acetaldehyde levels and this may lead to protection against alcoholism. We further demonstrated that the deficiency of ALDH I is widely prevalent among individuals of Mongoloid origin. More recent studies $[11,12]$ based on DNA analysis revealed that the cause for the isozyme deficiency could be a structural mutation leading to the synthesis of an enzymatically inactive protein. The present communication presents the methods for detecting ALDH isozyme polymorphism, the genetic implication of alcoholism and the incidence of the deficiency in different ethnic groups.

\section{Material and methods}

\subsection{Sample preparation}

Autopsy samples of liver, kidney, lung, muscle, heart, stomach, brain and spleen were obtained through routine autopsy 